\title{
LA DURACIÓN CONSONÁNTICA EN CASTELLANO
}

\author{
LAURA DEL BARRIO ESTÉVEZ -SERGIO TORNEL CASTELLS \\ (Universidad Autónoma de Barcelona -Universidad Pompeu Fabra)
}

This paper presents the results of an experimental analysis of the duration of Spanish consonants. The influence of three different factors - stress, location on the syllable, and pause vicinity - on the duration of consonants in reading text has been studied. Phonetic context and speech rate have also been controlled.

The obtained results seem to indicate that the vicinity of a pause and the location of the consonant in the syllable have a systematic effect on all the consonants, while the stress only affects the duration of a reduced set of voiced allophones ([1], $[r]$ and [n]). Some general conclusions about the mean duration of each consonant, and about the relationship between duration and voicing, manner and place of articulation, have also been established.

\section{Introducción}

Un sistema de síntesis de habla natural por reglas requiere un modelo de duración adecuado. Comprender y sistematizar cómo varían las duraciones de los segmentos en el decurso fónico es una de las tareas básicas a las que se enfrentan los investigadores dedicados en la actualidad a producir habla generada computacionalmente. Sin embargo, las investigaciones en el campo de la fonética experimental no han proporcionado todavía una descripción exhaustiva de los patrones temporales del sistema consonántico del castellano. Aunque tal información se encuentra actualmente implementada en sistemas de conversión de texto a habla, no se han publicado todavía los resultados de ningún análisis acústico que proporcione los datos imprescindibles para el diseño de un modelo de duración. 
El presente artículo" ofrece los resultados de un análisis experimental llevado a cabo en el Laboratorio de Fonética de la UAB que supone una primera aproximación al estudio de la duración consonántica en castellano peninsular. Para realizar esta investigación, se ha acotado el campo de análisis a la influencia de tres variables independientes sobre la duración de las consonantes en la lectura: el acento, la posición en la sílaba y la posición en el grupo fónico. No se han considerado las consonantes agrupadas ni las oclusivas, cuyas características temporales están siendo analizadas actualmente en el mismo Laboratorio de Fonética de la UAB.

Las consonantes que hemos incluido en nuestro estudio son las siguientes:

-Fricativas sordas: labiodental [f], interdental $[\theta]$, alveolar [s] y velar [ $\mathrm{x}]$.

-Fricativa palatal sonora $[\mathrm{y}]$ y alófono sonorizado de la fricativa alveolar [z].

-Africada palatal sorda [t $\mathrm{t}]$.

-Nasales: bilabial [m], alveolar [n] y palatal [n].

-Laterales: alveolar [1] y palatal $[\Lambda]$.

-Vibrantes: simple [ $\mathrm{r}$ y múltiple [r].

\section{Variables que inciden en las características temporales de las consonantes}

Una revisión de los trabajos dedicados a la duración consonántica tanto en castellano como en otras lenguas ha permitido determinar cuáles son los parámetros más significativos para elaborar un modelo de duración consonántica. Los resultados obtenidos por diversos autores indican que, como mínimo, deben tenerse en consideración tres variables:

- Acento (+ $/$ - acentuada)

- Posición en la sílaba $(+/$ - inicio de sílaba)

- Posición en el grupo fónico $(+/$ - prepausal)

El acento es uno de los parámetros cuyo análisis en los estudios sobre la duración consonántica se ha iniciado más recientemente; los resultados obtenidos son todavía poco homogéneos. Mientras que Duez \& Nishinuma (1987) constatan un alargamiento regular en las consonantes tónicas del francés, Crystal \& House (1988a) no lo aprecian para el inglés ni en las fricativas sordas ni en las nasales, pero sí en las demás consonantes; en italiano, Farnetani \& Kori (1984) observan una mayor duración de las consonantes iniciales de palabra en sílaba tónica. Para el

\footnotetext{
* Una versión anterior y más reducida de este trabajo fue presentada en el XXV Simposio de la Sociedad Española de Lingilística celebrado en Zaragoza los días 11 al 14 de Diciembre de 1995.

La investigación necesaria para desarrollar este trabajo ha sido parcialmente financiada con una beca Fl/95-2.130 concedida por la Direcció General de Recerca de la Generalitat de Catalunya y con el apoyo del Comissionat per Universitats i Recerca de la Generalitat de Catalunya $\left(\mathrm{n}^{\circ}\right.$ de referencia GRQ94-2006).
} 
castellano, los estudios de Borzone de Manrique \& Signorini (1983) —realizados con locutores argentinos - parecen revelar un alargamiento sistemático de las consonantes acentuadas, pero el estudio de Ríos (1991) dedicado a la sílaba concluye que el carácter acentual de la sílaba no produce diferencias duracionales significativas en las consonantes.

Por lo que concierne a la posición de la consonante en la sílaba, Farnetani \& Kori (1984) encuentran que en italiano las consonantes en posición final de sílaba son algo más largas que las consonantes aisladas en posición intervocálica. Campbell \& Isard (1991) llegan a una conclusión similar en su estudio dedicado al inglés, y defienden, además, que en esta posición las consonantes presentan alargamientos mayores.

Finalmente, la posición del segmento en el grupo fónico es uno de los aspectos más extensamente analizados y acerca del cual existe un mayor consenso: la duración aumenta cuando un sonido se encuentra en posición prepausal. Este fenómeno recibe el nombre de Prepausal Lenghtening Effect (PLE) o alargamiento prepausal. Todos los estudios coinciden en afirmar que, sin duda, este efecto tiene lugar en los sonidos vocálicos; sin embargo, no existe acuerdo sobre cuál es la influencia de las pausas en la duración de las consonantes.

Oller (1973) y Klatt (1975) para el inglés y O’Shaughnessy (1984) para el francés detectan el PLE solamente en algunas consonantes sonoras y en algunas fricativas, mientras que Umeda (1977) defiende que en inglés el alargamiento se produce en todas las consonantes excepto en [t] y [d]; Luce \& Charles-Luce (1985) y Crystal \& House (1988a) arguyen, por su parte, que el alargamiento también se produce en las oclusivas.

Para el castellano, Borzone de Manrique \& Signorini (1983) también constatan un alargamiento de las consonantes en posición prepausal y Navarro Tomás (1918) resalta el aumento de la duración que experimenta [1] en este contexto. A su vez, Ríos (1991) detecta un alargamiento claro de la sílaba cuando se halla en posición prepausal.

\section{Protocolo experimental}

\subsection{Variables estudiadas}

Con el fin de dar sistematicidad al análisis, se han definido las condiciones que caracterizan los distintos valores de cada una de las variables estudiadas del siguiente modo:

(1) Se considera que una consonante es [+ acentuada] cuando se halla en una sílaba tónica. Entendemos por sílaba tónica una sílaba con acento léxico primario; por tanto, se excluyen como consonantes acentuadas aquellas que se hallan en sílabas que puedan recibir acentos secundarios en el decurso fónico, y, 
en cambio, se incluyen las que aparecen en una sílaba que posea un acento léxico que se haya convertido en el decurso en acento secundario.

(2) Por lo que se refiere a la posición en la sílaba, se distinguen dos valores: «inicio de sílaba» frente a «final de sílaba». No se han considerado en este experimento las consonantes finales de palabra que por resilabificación pasan a formar parte del ataque de la sílaba siguiente; luego sólo se han tenido en cuenta aquellas consonantes cuyo carácter de ataque o coda silábica no depende de factores discursivos.

(3) En cuanto a la posición de la consonante en el grupo fónico, se han tenido en cuenta dos valores: «prepausal»vs. «no prepausal». Tomamos como prepausal toda consonante que esté en posición de ataque o coda de sílaba prepausal; es decir, que esté en la sílaba que precede a una pausa sintáctica o final de frase - tanto si la pausa tiene correlato ortográfico como si no lo tiene $^{1}$.

\subsection{Variables controladas}

Más allá de las variables estudiadas, existen otras cuyo influjo en la duración consonántica no se estudia pero que, en cambio, se han controlado al confeccionar el corpus, dado que la bibliografía especializada contempla que tal vez podrían afectar a la duración de los elementos consonánticos. Estas variables son la velocidad de elocución y el contexto.

\subsubsection{Velocidad de elocución}

Para evitar excesivas diferencias en la velocidad de elocución de las grabaciones, antes de efectuarlas se dieron instrucciones explícitas a los informantes para que leyeran los textos a velocidad normal. Antes de realizar el análisis estadístico de los datos, se comprobó que no existieran diferencias estadísticamente significativas entre las velocidades de elocución de los dos informantes seleccionados. Las pruebas estadísticas revelaron que estás diferencias existían y eran significativas, por lo cual se tuvieron que normalizar los datos a una velocidad estandarizada de 6,5 sílabas por segundo antes de iniciar el tratamiento estadístico de los datos obtenidos.

\footnotetext{
${ }^{1}$ En este campo se ha discutido si el alargamiento prepausal podría afectar también a la sílaba anterior a la prepausal. Aunque no hay unanimidad en los resultados, los autores que defienden la existencia de dicho efecto cn la penúltima sílaba del decurso fónico coinciden en afirmar que sólo se detecta en cl núcleo silábico y de forma mucho más tenue que en la sílaba prepausal. Por lo tanto, creemos que es lícito ignorar esta variable en el estudio de las consonantes, puesto que éstas no quedan nunca afectadas por el alargamiento prepausal cuando están en la sílaba anterior a la última del grupo fónico.
} 


\subsubsection{Contexto}

Se han controlado tres variables contextuales: el timbre del núcleo silábico, el contexto de la consonante en ataque silábico y el contexto de la consonante en coda.

Timbre del núcleo silábico. Algunos estudios (Schwartz, 1969; Amerman \& Parnell, 1992; O'Shaughnessy, 1981) defienden que el timbre vocálico afecta a la duración, fenómeno que se manifiesta en un alargamiento de las consonantes en contacto con vocales altas. Por ello se ha considerado oportuno controlar el timbre del núcleo de la sílaba en que se encuentra la consonante analizada. Dado que son las vocales altas las que modifican la duración consonántica, se decidió que el núcleo de la sílaba en que está la consonante fuera siempre [a], cosa que se ha conseguido en todos los casos excepto para $[\mathrm{x}]$ en posición final.

Contexto de la consonante en ataque silábico. Las consonantes analizadas en ataque aparecen siempre en contexto intervocálico.

Contexto de la consonante en coda silábica. En español, sólo se registran consonantes en coda silábica si la siguiente sílaba empieza también por consonante ${ }^{2}$. Se ha controlado que esta consonante fuera siempre una oclusiva para evitar así variaciones en la duración debidas a la naturaleza de la consonante siguiente.

\subsection{Corpus}

Los datos para la investigación se han extraído de un corpus de lectura constituido por seis textos aparecidos en periódicos de ámbito nacional; todos se han elegido de una misma sección - la económica - para conseguir un registro uniforme ${ }^{3}$. Con el fin de obtener el mayor número de casos posibles para todas las consonantes y cada una de las variables, los textos periodísticos utilizados se han retocado convenientemente, respetando el estilo y el léxico específicos del artículo; aún así ha sido imposible encontrar el mismo número de ejemplos para todas las consonantes, aunque la mayoría de las veces cada caso cuenta con cinco o más ejemplos. No obstante hay que tener en cuenta que existen contextos en los que ciertas consonantes del castellano presentan distribución defectiva. Este es el caso de $[\mathrm{r}],[\mathrm{n}],[\Lambda],[\mathrm{y}]$ y $\left[\mathrm{t} \int\right]$, inexistentes en posición de coda silábica. En este mismo contexto, $[\mathrm{m}]$ sólo aparece por asimilación, y $[\mathrm{z}]$ si precede a una consonante sonora, de lo que se colige que no se podrán registrar en contexto prepausal. Tampoco encontramos en castellano $[\theta]$ y $[x]$ al final de una palabra cuya última sílaba sea átona y tenga por núcleo silábico la vocal [a], por lo que no hay ejemplos de $[x]$ y $[\theta]$ prepausales acentuadas en nuestro estudio.

\footnotetext{
${ }^{2}$ Véanse al respecto Alarcos (1971: $\$ \$ 120-126$ bis) y Harris (1991: 78-81).

${ }^{3}$ El conjunto de los seis textos constituye un corpus que consta de 3.237 palabras. La elección de un corpus de lectura queda justificada por la pretensión de utilizar los resultados del estudio cn la confección de un modelo válido para un conversor de texto a habla.
} 


\subsection{Informantes}

La selección de informantes se ha llevado a cabo teniendo en cuenta el sexo, la edad, la lengua materna y el nivel cultural. El perfil de los dos locutores seleccionados es el siguiente: varones de entre 30 y 45 años cuya lengua materna es el castellano y con titulación universitaria.

Cada informante leyó varias veces los textos antes de la grabación para familiarizarse con ellos; de este modo se aseguraba una lectura más fluida y con menos errores, y una mayor uniformidad en el ritmo.

\subsection{Grabación}

La grabación se ha realizado en una cámara semianecoica con un magnetófono Tascam. Teac Profesional Division 112 que posee una respuesta frecuencial de 25 $\mathrm{KHz} .+/-3 \mathrm{~dB}$. y un micrófono omnidireccional Senheiser MKH2OP48U3, con una respuesta de frecuencia de $20 \mathrm{~Hz}$. a $20 \mathrm{Khz}$.

\subsection{Análisis acústico}

\section{Instrumental}

El estudio acústico se ha llevado a cabo con el programa Mac Speech Lab II (6w Instruments) para ordenadores Macintosh.

\section{Segmentación}

La segmentación de los sonidos para calcular su duración se ha realizado a partir de representaciones oscilográficas y espectográficas de la onda sonora; estos últimos han sido de gran ayuda en el momento de determinar la duración de los sonidos con transiciones largas. En la segmentación, se ha decidido incluir en la consonante todos los ciclos que sean propiamente consonánticos, procurando que la segmentación tome siempre ciclos completos. Cuando la transición es muy larga, hemos considerado que pertenecen a la vocal aquellos ciclos en los que aún se aprecia una estructura vocálica clara ${ }^{4}$. Con ello, seguimos el mismo criterio de segmentación que Borzone \& Signorini (1983) y que Toledo (1988), pero no el mismo que Delattre (1966) y Olsen (1972).

\section{Velocidad de elocución}

Se ha controlado que el ritmo de lectura de cada informante durante la grabación sea uniforme. No obstante, se ha creido oportuno realizar un estudio estadístico que determinara si existían diferencias significativas entre la velocidad de elocución de los dos informantes. Para ello se han tomado de las respectivas grabaciones de cada informante tres muestras de dos segundos de cada uno de los textos, al inicio, medio

\footnotetext{
${ }^{4}$ De este modo, nuestro estudio se configura como complementario al análisis sobre la duración vocálica que llevó a cabo R. Marín (1994-95), en el que se seguía este mismo criterio en la segmentación de los sonidos vocálicos.

${ }^{5}$ Trabajo éste citado por Ríos (1991).
} 
y fin de los mismos; se ha evitado que estas muestras contuvieran pausas, porque distintos estudios (Goldman-Eisler, 1968; Gay et al., 1974; Cristal \& House, 1982) han demostrado que la velocidad de elocución incide mayoritariamente en la duración de éstas. Se ha contado cuántas sílabas pronunciaban los informantes en las diversas muestras extraídas de los textos, considerando como única cualquier sílaba formada por más de una sílaba teórica mediante procesos fonológicos de sinéresis. El estudio en cuestión ha demostrado que la velocidad de elocución de ambos informantes es distinta y una comparación mediante el $t$-test de Student pone de manifiesto que, además, estas diferencias son estadísticamente significativas:

Informante 1:5,94 sílabas / segundo

Informante 2: 6,83 sílabas / segundo

Por este motivo, se ha decidido normalizar, con una simple regla de tres, las duraciones a una velocidad estandarizada de 6,5 sílabas por segundo antes de iniciar el estudio estadístico de los datos obtenidos.

\subsection{Tratamiento estadístico}

Para el tratamiento estadístico se ha utilizado el programa Stat View con el cual se han calculado las duraciones medias y se han realizado los análisis de significación.

\section{Resultados}

\subsection{Duración media}

La Figura 1 presenta las duraciones medias de cada una de las consonantes, de cuya comparación se pueden extraer algunas conclusiones de carácter general. La consonante más larga de las estudiadas es la africada, con una duración media de 117 ms.; a continuación se sitúan las fricativas sordas que oscilan entre 100 y 115 ms. Y, en un orden de mayor a menor duración, el resto de consonantes presenta estas duraciones: [r] 96 ms.; nasales, entre 74 y 90 ms.; fricativas sonoras, unos 60 ms.; laterales, de 59 a 67 ms. y, por último, [r], con una duración de $46 \mathrm{~ms}$.

Se observa, por tanto, que existe una relación entre sonoridad y duración: las consonantes sordas son, en conjunto, más largas que las sonoras ${ }^{6}$. Parece también que las nasales y las laterales presentan una correlación entre el punto de articulación y la duración, de tal manera que las que tienen un punto de articulación más avanzado son más breves.

\footnotetext{
${ }^{6}$ Es arriesgado, no obstante, sacar conclusiones taxativas en este sentido, puesto que no existe una africada sonora, ni hemos estudiado los equivalentes sonoros de $[\mathrm{f}]$ y $[\theta]$; en rigor sólo es comparable la cantidad de [s] y [z].
} 


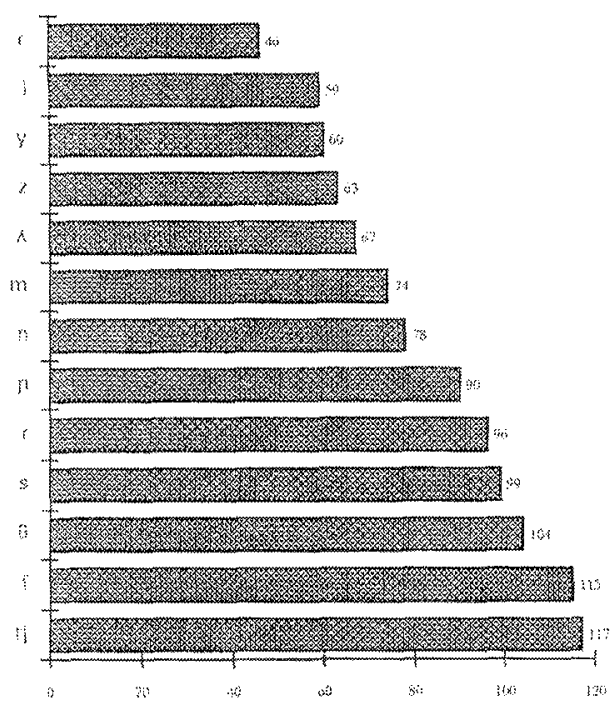

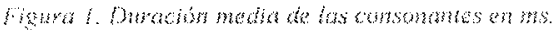

La TABLA $I$ resume las duraciones de cada consonante desglosadas por contextos y pone de manifiesto un dato significativo: la mayoría de las consonantes registran su más breve duración en inicio de sílaba átona y en posición no prepausal. Este comportamiento de los segmentos consonánticos del castellano podría aducirse como prueba a favor de la teoría que postula Klatt (1976) según la cual todos los segmentos tienen una duración intrínseca propia. Podría asumirse que esta duración intrínseca es la menor del segmento y que se incrementa por la interacción de múltiples factores que inciden en ella. Este dato se debe tener en cuenta si se quiere construir un modelo - aditivo o multiplicativo- de la duración de las consonantes en castellano. No obstante, hay dos consonantes, [s] y [n], que no siguen este patrón: [n] es más breve cuando aparece en inicio de sílaba no prepausal, pero en sílaba tónica; [s] muestra su realización menor en el contexto [+ acento, - inicio sílaba, - prepausal] $]^{7}$.

\footnotetext{
${ }^{7}$ Sin embargo, cabe interpretar este comportamiento dispar de [n] y [s] en función de los resultados que se desprenden de nuestro estudio. En primer lugar, ninguno de estos sonidos queda afectado por el valor acentual de la sílaba; en segundo lugar, la duración de [s] no presenta diferencias estadísticamente significativas en función de su posición en la sílaba. Por tanto, aunque no se puede ignorar que estas
} 
TABLA I. Duración consonántica según el acento, la posición en la sílaba y la posición en el

\begin{tabular}{|c|c|c|c|c|c|c|c|c|c|c|}
\hline \multirow{2}{*}{\multicolumn{2}{|c|}{$\begin{array}{l}\text { Accnto } \\
\text { Inicio de sílaba }\end{array}$}} & \multicolumn{4}{|c|}{+} & \multicolumn{4}{|c|}{-} & \multirow[t]{3}{*}{ Total } \\
\hline & & \multicolumn{2}{|r|}{+} & \multicolumn{2}{|r|}{ E } & \multicolumn{2}{|c|}{+} & \multicolumn{2}{|r|}{-} & \\
\hline Prepa & & + & - & + & - & + & - & + & - & \\
\hline$r$ & $\begin{array}{l}\mathrm{N} \\
\mathrm{ms} .\end{array}$ & $\begin{array}{c}9 \\
27 \\
\end{array}$ & $\begin{array}{l}15 \\
29 \\
\end{array}$ & $\begin{array}{l}17 \\
81 \\
\end{array}$ & $\begin{array}{l}10 \\
52 \\
\end{array}$ & $\begin{array}{c}9 \\
33 \\
\end{array}$ & $\begin{array}{l}10 \\
27\end{array}$ & $\begin{array}{c}2 \\
68 \\
\end{array}$ & $\begin{array}{l}10 \\
48 \\
\end{array}$ & $\begin{array}{l}82 \\
46 \\
\end{array}$ \\
\hline$r$ & $\begin{array}{l}\mathrm{N} \\
\mathrm{ms}\end{array}$ & $\begin{array}{c}6 \\
103 \\
\end{array}$ & $\begin{array}{c}8 \\
86\end{array}$ & $\begin{array}{l}0 \\
*\end{array}$ & $\begin{array}{l}0 \\
*\end{array}$ & $\begin{array}{c}8 \\
111\end{array}$ & $\begin{array}{c}8 \\
84\end{array}$ & $\begin{array}{l}0 \\
*\end{array}$ & $\begin{array}{l}0 \\
*\end{array}$ & $\begin{array}{l}30 \\
96\end{array}$ \\
\hline$m$ & $\begin{array}{l}\mathrm{N} \\
\mathrm{ms}\end{array}$ & $\begin{array}{l}10 \\
80 \\
\end{array}$ & $\begin{array}{l}16 \\
68 \\
\end{array}$ & $\begin{array}{l}0 \\
* \\
\end{array}$ & $\begin{array}{l}10 \\
76 \\
\end{array}$ & $\begin{array}{c}8 \\
79 \\
\end{array}$ & $\begin{array}{l}11 \\
66 \\
\end{array}$ & $\begin{array}{l}0 \\
* \\
\end{array}$ & $\begin{array}{l}10 \\
78 \\
\end{array}$ & $\begin{array}{l}65 \\
74 \\
\end{array}$ \\
\hline$n$ & $\begin{array}{l}\mathrm{N} \\
\mathrm{ms} .\end{array}$ & $\begin{array}{l}10 \\
66 \\
\end{array}$ & $\begin{array}{l}10 \\
62\end{array}$ & $\begin{array}{c}10 \\
148\end{array}$ & $\begin{array}{l}12 \\
73\end{array}$ & $\begin{array}{l}10 \\
58\end{array}$ & $\begin{array}{l}19 \\
59\end{array}$ & $\begin{array}{c}8 \\
120 \\
\end{array}$ & $\begin{array}{l}21 \\
71 \\
\end{array}$ & $\begin{array}{c}100 \\
78 \\
\end{array}$ \\
\hline $\mathrm{j}$ & $\begin{array}{l}\mathrm{N} \\
\mathrm{ms} .\end{array}$ & $\begin{array}{c}6 \\
102\end{array}$ & $\begin{array}{l}11 \\
71\end{array}$ & $\begin{array}{l}0 \\
*\end{array}$ & $\begin{array}{l}0 \\
*\end{array}$ & $\begin{array}{c}11 \\
105\end{array}$ & $\begin{array}{l}12 \\
89\end{array}$ & $\begin{array}{l}0 \\
*\end{array}$ & $\begin{array}{l}0 \\
*\end{array}$ & $\begin{array}{l}40 \\
90\end{array}$ \\
\hline 1 & $\begin{array}{l}\mathrm{N} \\
\mathrm{ms} .\end{array}$ & $\begin{array}{c}8 \\
53\end{array}$ & $\begin{array}{c}9 \\
44\end{array}$ & $\begin{array}{c}11 \\
103\end{array}$ & $\begin{array}{c}8 \\
52\end{array}$ & $\begin{array}{c}2 \\
81\end{array}$ & $\begin{array}{l}13 \\
42\end{array}$ & $\begin{array}{c}2 \\
84\end{array}$ & $\begin{array}{l}10 \\
47\end{array}$ & $\begin{array}{l}63 \\
59\end{array}$ \\
\hline $\bar{\Lambda}$ & $\begin{array}{l}\mathrm{N} \\
\mathrm{ms}\end{array}$ & $\begin{array}{c}8 \\
78 \\
\end{array}$ & $\begin{array}{c}9 \\
62 \\
\end{array}$ & $\begin{array}{l}0 \\
* \\
\end{array}$ & $\begin{array}{l}0 \\
* \\
\end{array}$ & $\begin{array}{c}7 \\
70 \\
\end{array}$ & $\begin{array}{l}10 \\
61 \\
\end{array}$ & $\begin{array}{l}0 \\
* \\
\end{array}$ & $\begin{array}{l}0 \\
* \\
\end{array}$ & $\begin{array}{l}34 \\
67\end{array}$ \\
\hline $\mathrm{f}$ & \begin{tabular}{|l}
$\mathrm{N}$ \\
$\mathrm{ms}$.
\end{tabular} & $\begin{array}{c}4 \\
125 \\
\end{array}$ & $\begin{array}{c}10 \\
101 \\
\end{array}$ & $\begin{array}{l}0 \\
* \\
\end{array}$ & $\begin{array}{l}0 \\
* \\
\end{array}$ & $\begin{array}{c}12 \\
139 \\
\end{array}$ & $\begin{array}{c}9 \\
93 \\
\end{array}$ & $\begin{array}{l}0 \\
* \\
\end{array}$ & $\begin{array}{l}0 \\
* \\
\end{array}$ & $\begin{array}{c}35 \\
115 \\
\end{array}$ \\
\hline$\theta$ & $\begin{array}{l}\mathrm{N} \\
\mathrm{ms}\end{array}$ & $\begin{array}{c}9 \\
105\end{array}$ & $\begin{array}{c}11 \\
106\end{array}$ & $\begin{array}{c}9 \\
131 \\
\end{array}$ & $\begin{array}{l}10 \\
91 \\
\end{array}$ & $\begin{array}{c}4 \\
120 \\
\end{array}$ & $\begin{array}{l}11 \\
86 \\
\end{array}$ & $\begin{array}{l}0 \\
* \\
\end{array}$ & $\begin{array}{l}0 \\
* \\
\end{array}$ & $\begin{array}{c}54 \\
104 \\
\end{array}$ \\
\hline$S$ & \begin{tabular}{|l|}
$\mathrm{N}$ \\
$\mathrm{ms}$.
\end{tabular} & $\begin{array}{c}3 \\
83 \\
\end{array}$ & $\begin{array}{l}10 \\
96 \\
\end{array}$ & $\begin{array}{c}10 \\
133 \\
\end{array}$ & $\begin{array}{l}10 \\
63 \\
\end{array}$ & $\begin{array}{c}7 \\
108 \\
\end{array}$ & $\begin{array}{c}10 \\
103 \\
\end{array}$ & $\begin{array}{c}15 \\
118 \\
\end{array}$ & $\begin{array}{c}9 \\
69 \\
\end{array}$ & $\begin{array}{l}74 \\
99 \\
\end{array}$ \\
\hline $\mathrm{z}$ & $\begin{array}{l}\mathrm{N} \\
\mathrm{ms} .\end{array}$ & $\begin{array}{l}0 \\
*\end{array}$ & $\begin{array}{l}0 \\
*\end{array}$ & $\begin{array}{l}0 \\
*\end{array}$ & $\begin{array}{l}10 \\
63\end{array}$ & $\begin{array}{l}0 \\
*\end{array}$ & $\begin{array}{l}0 \\
*\end{array}$ & $\begin{array}{l}0 \\
*\end{array}$ & $\begin{array}{l}11 \\
63\end{array}$ & $\begin{array}{l}21 \\
63\end{array}$ \\
\hline$y$ & $\begin{array}{l}\mathrm{N} \\
\mathrm{ms} .\end{array}$ & $\begin{array}{c}4 \\
59\end{array}$ & $\begin{array}{c}8 \\
57\end{array}$ & $\begin{array}{l}0 \\
* \\
\end{array}$ & $\begin{array}{l}0 \\
* \\
\end{array}$ & $\begin{array}{c}6 \\
78\end{array}$ & $\begin{array}{l}15 \\
55\end{array}$ & $\begin{array}{l}0 \\
* \\
\end{array}$ & $\begin{array}{l}0 \\
*\end{array}$ & $\begin{array}{l}33 \\
60\end{array}$ \\
\hline$x$ & $\begin{array}{l}\mathrm{N} \\
\mathrm{m} \text {. }\end{array}$ & $\begin{array}{c}7 \\
128 \\
\end{array}$ & $\begin{array}{c}10 \\
100 \\
\end{array}$ & $\begin{array}{c}2 \\
145 \\
\end{array}$ & $\begin{array}{c}1 \\
94 \\
\end{array}$ & $\begin{array}{c}8 \\
125 \\
\end{array}$ & $\begin{array}{c}9 \\
90 \\
\end{array}$ & $\begin{array}{l}0 \\
* \\
\end{array}$ & $\begin{array}{l}0 \\
* \\
\end{array}$ & $\begin{array}{c}37 \\
111 \\
\end{array}$ \\
\hline tf & $\begin{array}{l}\mathrm{N} \\
\mathrm{ms} .\end{array}$ & $\begin{array}{c}6 \\
132 \\
\end{array}$ & $\begin{array}{c}8 \\
107 \\
\end{array}$ & $\begin{array}{l}0 \\
*\end{array}$ & $\begin{array}{l}0 \\
*\end{array}$ & $\begin{array}{c}6 \\
155\end{array}$ & $\begin{array}{l}10 \\
95\end{array}$ & $\begin{array}{l}0 \\
* \\
\end{array}$ & $\begin{array}{l}0 \\
* \\
\end{array}$ & $\begin{array}{c}30 \\
117 \\
\end{array}$ \\
\hline Total & $\begin{array}{l}\mathrm{N} \\
\mathrm{ms} .\end{array}$ & $\begin{array}{l}90 \\
84\end{array}$ & $\begin{array}{c}135 \\
74\end{array}$ & $\begin{array}{c}59 \\
115\end{array}$ & $\begin{array}{l}71 \\
68\end{array}$ & $\begin{array}{l}98 \\
97\end{array}$ & $\begin{array}{c}147 \\
71\end{array}$ & $\begin{array}{c}27 \\
115\end{array}$ & $\begin{array}{l}71 \\
64\end{array}$ & $\begin{array}{c}698 \\
81\end{array}$ \\
\hline
\end{tabular}

grupo fónico. $\mathrm{N}$ número de casos ms duración media en milisegundos.

A continuación se examinará cómo influye cada una de las variables consideradas en la duración de los sonidos consonánticos. Para llevar a cabo este

diferencias existen si se quieren extraer conclusiones teóricas del estudio, hay que tener en cuenta quc dichas diferencias no son estadísticamente significativas. 
estudio hemos agrupado las consonantes en grupos para facilitar el manejo de los datos. A fin de establecer estos subgrupos se ha realizado un análisis de varianza (ANOVA) que compara la duración de las consonantes entre sí. Este cotejo muestra que las consonantes se agrupan naturalmente en subclases entre cuyos elementos no existen diferencias de duración estadísticamente significativas; en cambio, sí existen diferencias significativas entre los miembros de subclases distintas. Las subclases que se han obtenido con este análisis son las siguientes: fricativas sordas, fricativas sonoras, $[\mathrm{m}]$ y $[\mathrm{n}],[\mathrm{n}],[\mathrm{r}],[\mathrm{r}]$, africada, laterales.

El estudio estadístico se ha llevado a cabo considerando la categoría subclase de sonido y no la categoría consonante. La duración media de dichas subclases consonánticas para cada contexto es la que aparece en la TABLA 2.

\begin{tabular}{|c|c|c|c|c|c|c|c|c|c|c|}
\hline \multirow{3}{*}{\multicolumn{2}{|c|}{\begin{tabular}{|l|} 
Acento \\
Inicio sílaba \\
Prenausal \\
\end{tabular}}} & \multicolumn{4}{|c|}{+} & & & & & \multirow[t]{3}{*}{ Total } \\
\hline & & \multicolumn{2}{|c|}{+} & & \multicolumn{2}{|c|}{+} & \multicolumn{2}{|c|}{ - } & \\
\hline & & + & - & + & - & + & - & + & - & \\
\hline $\begin{array}{l}\text { Fricativa } \\
\text { sonoras }\end{array}$ & $\begin{array}{l}\mathrm{n} \\
\mathrm{ms} .\end{array}$ & $\begin{array}{c}5 \\
68\end{array}$ & $\begin{array}{c}8 \\
66\end{array}$ & $\begin{array}{l}0 \\
*\end{array}$ & $\begin{array}{l}10 \\
63\end{array}$ & $\begin{array}{c}6 \\
78\end{array}$ & $\begin{array}{l}15 \\
55\end{array}$ & $\begin{array}{l}0 \\
*\end{array}$ & $\begin{array}{l}11 \\
63\end{array}$ & $\begin{array}{l}55 \\
63\end{array}$ \\
\hline \begin{tabular}{|l|} 
Fricativa \\
sordas
\end{tabular} & $\begin{array}{l}\mathrm{n} \\
\mathrm{ms} .\end{array}$ & $\begin{array}{c}22 \\
113\end{array}$ & $\begin{array}{c}41 \\
101\end{array}$ & $\begin{array}{c}21 \\
133\end{array}$ & $\begin{array}{l}21 \\
78\end{array}$ & $\begin{array}{c}31 \\
126\end{array}$ & $\begin{array}{l}39 \\
93\end{array}$ & $\begin{array}{c}15 \\
118\end{array}$ & $\begin{array}{c}9 \\
69\end{array}$ & $\begin{array}{l}199 \\
105\end{array}$ \\
\hline $\mathrm{m} / \mathrm{n}$ & $\begin{array}{l}\mathrm{n} \\
\mathrm{ms} .\end{array}$ & $\begin{array}{l}20 \\
73\end{array}$ & $\begin{array}{l}26 \\
66\end{array}$ & $\begin{array}{c}10 \\
148\end{array}$ & $\begin{array}{l}22 \\
74\end{array}$ & $\begin{array}{l}18 \\
63\end{array}$ & $\begin{array}{l}30 \\
62\end{array}$ & $\begin{array}{c}8 \\
120\end{array}$ & $\begin{array}{l}31 \\
73\end{array}$ & $\begin{array}{c}165 \\
76\end{array}$ \\
\hline $\mathrm{n}$ & $\begin{array}{l}\mathrm{n} \\
\mathrm{ms} .\end{array}$ & $\begin{array}{c}6 \\
102 \\
\end{array}$ & $\begin{array}{l}11 \\
71\end{array}$ & $\begin{array}{l}0 \\
*\end{array}$ & $\begin{array}{l}0 \\
*\end{array}$ & $\begin{array}{c}11 \\
105\end{array}$ & $\begin{array}{l}12 \\
89\end{array}$ & $\begin{array}{l}0 \\
*\end{array}$ & $\begin{array}{l}0 \\
*\end{array}$ & $\begin{array}{l}40 \\
90\end{array}$ \\
\hline r & $\begin{array}{l}\mathrm{n} \\
\mathrm{ms} .\end{array}$ & $\begin{array}{c}9 \\
27 \\
\end{array}$ & $\begin{array}{l}15 \\
29 \\
\end{array}$ & $\begin{array}{l}17 \\
81\end{array}$ & $\begin{array}{l}10 \\
52 \\
\end{array}$ & $\begin{array}{r}9 \\
33 \\
\end{array}$ & $\begin{array}{c}10 \\
27,5 \\
\end{array}$ & $\begin{array}{c}2 \\
68 \\
\end{array}$ & $\begin{array}{l}10 \\
48 \\
\end{array}$ & $\begin{array}{l}82 \\
46 \\
\end{array}$ \\
\hline $\mathrm{r}$ & $\begin{array}{l}\mathrm{n} \\
\mathrm{ms} .\end{array}$ & $\begin{array}{c}6 \\
103\end{array}$ & $\begin{array}{c}8 \\
86\end{array}$ & $\begin{array}{l}0 \\
*\end{array}$ & $\begin{array}{l}0 \\
*\end{array}$ & $\begin{array}{c}8 \\
111\end{array}$ & $\begin{array}{c}8 \\
84\end{array}$ & $\begin{array}{l}0 \\
*\end{array}$ & $\begin{array}{l}0 \\
*\end{array}$ & $\begin{array}{l}30 \\
96\end{array}$ \\
\hline ts & $\begin{array}{l}\mathrm{n} \\
\mathrm{ms} .\end{array}$ & $\begin{array}{c}6 \\
132 \\
\end{array}$ & $\begin{array}{c}8 \\
106 \\
\end{array}$ & $\begin{array}{l}0 \\
*\end{array}$ & $\begin{array}{l}0 \\
*\end{array}$ & $\begin{array}{c}6 \\
154 \\
\end{array}$ & $\begin{array}{l}10 \\
95\end{array}$ & $\begin{array}{l}0 \\
*\end{array}$ & $\begin{array}{l}0 \\
*\end{array}$ & $\begin{array}{c}30 \\
117 \\
\end{array}$ \\
\hline Laterales & $\begin{array}{l}\mathrm{n} \\
\mathrm{ms} .\end{array}$ & $\begin{array}{l}16 \\
65 \\
\end{array}$ & $\begin{array}{l}18 \\
53 \\
\end{array}$ & $\begin{array}{c}11 \\
103 \\
\end{array}$ & $\begin{array}{c}8 \\
52 \\
\end{array}$ & $\begin{array}{c}9 \\
73 \\
\end{array}$ & $\begin{array}{l}23 \\
50 \\
\end{array}$ & $\begin{array}{c}2 \\
68 \\
\end{array}$ & $\begin{array}{l}10 \\
47 \\
\end{array}$ & $\begin{array}{l}97 \\
60 \\
\end{array}$ \\
\hline Total & $\begin{array}{l}\mathrm{n} \\
\mathrm{ms} .\end{array}$ & $\begin{array}{l}90 \\
84\end{array}$ & $\begin{array}{c}135 \\
74\end{array}$ & $\begin{array}{c}59 \\
115\end{array}$ & $\begin{array}{l}71 \\
68\end{array}$ & $\begin{array}{l}98 \\
97\end{array}$ & $\begin{array}{c}147 \\
71\end{array}$ & $\begin{array}{c}27 \\
115\end{array}$ & $\begin{array}{l}71 \\
64\end{array}$ & $\begin{array}{c}698 \\
81\end{array}$ \\
\hline
\end{tabular}

TABLA 2. Duración de las subclases consonánticas según el acento, la posición en la silaba y la posición en el grupo fónico.n número de casos ms. duración media en milisegundos

En los siguientes epígrafes se estudiará cómo afecta cada variable a la duración de las distintas subclases de sonidos. 


\subsection{Influencia del acento}

El estudio de la incidencia del acento en la duración consonántica del castellano no ofrece resultados homogéneos. El t-test (vid. TABLA 3) revela que la diferencia en la duración de las consonantes acentuadas frente a las no acentuadas no es estadísticamente significativa en la mayoría de los casos; un simple cotejo de las duraciones medias obtenidas para cada subclase pone de manifiesto que las diferencias, cuando existen, son mínimas.

\begin{tabular}{|c|c|c|c|c|}
\hline Subclase & & [+ Acento] & [- Acento] & $\mathrm{P}$ \\
\hline $\begin{array}{c}\text { Fricativas } \\
\text { sonoras }\end{array}$ & $\begin{array}{l}\mathrm{n} \\
\mathrm{ms} .\end{array}$ & $\begin{array}{l}23 \\
62\end{array}$ & $\begin{array}{l}32 \\
62\end{array}$ & 0,9974 \\
\hline $\begin{array}{c}\text { Fricativas } \\
\text { sordas }\end{array}$ & $\begin{array}{l}\mathrm{n} \\
\mathrm{ms} .\end{array}$ & $\begin{array}{l}104 \\
105\end{array}$ & $\begin{array}{c}95 \\
106\end{array}$ & 0,9701 \\
\hline $\mathrm{m} / \mathrm{n}$ & $\begin{array}{l}\mathrm{n} \\
\mathrm{ms} .\end{array}$ & $\begin{array}{l}78 \\
80 \\
\end{array}$ & $\begin{array}{l}87 \\
72 \\
\end{array}$ & 0,0507 \\
\hline $\mathrm{n}$ & $\begin{array}{l}\mathrm{n} \\
\mathrm{ms} .\end{array}$ & $\begin{array}{l}17 \\
82 \\
\end{array}$ & $\begin{array}{l}23 \\
97 \\
\end{array}$ & 0,0939 \\
\hline r & $\begin{array}{l}\mathrm{n} \\
\mathrm{ms} .\end{array}$ & $\begin{array}{l}51 \\
51\end{array}$ & $\begin{array}{l}31 \\
38\end{array}$ & 0,0368 \\
\hline$r$ & $\begin{array}{l}\text { n } \\
\text { ms. }\end{array}$ & $\begin{array}{l}14 \\
93\end{array}$ & $\begin{array}{l}16 \\
97\end{array}$ & 0,7236 \\
\hline is & $\begin{array}{l}\mathrm{n} \\
\mathrm{ms} .\end{array}$ & $\begin{array}{c}14 \\
117 \\
\end{array}$ & $\begin{array}{r}16 \\
117 \\
\end{array}$ & 0,9842 \\
\hline Laterales & $\begin{array}{l}\mathrm{n} \\
\mathrm{ms} .\end{array}$ & $\begin{array}{l}53 \\
67 \\
\end{array}$ & $\begin{array}{l}44 \\
52\end{array}$ & 0,0021 \\
\hline Total & $\begin{array}{l}\mathrm{n} \\
\mathrm{ms}\end{array}$ & $\begin{array}{c}355 \\
82 \\
\end{array}$ & $\begin{array}{r}343 \\
80 \\
\end{array}$ & 0,4296 \\
\hline
\end{tabular}

TABLA 3. Duración según el acento.

El análisis estadístico manifiesta que sólo existen variaciones significativas en la vibrante simple y en las laterales; en las nasales el valor de $p$ obtenido en el $t$-test apenas supera el 0,05 que se suele tomar como el valor a partir del cual dos conjuntos de datos no se pueden considerar distintos. Para los grupos en los que el acento tiene o puede tener incidencia en la duración, se ha repetido el estudio realizado atendiendo ahora a cada consonante por separado. Los resultados a los que se ha llegado son los que recoge la $T A B L A$ 4, donde se refleja que la variable $[+/-$ ac.] influye, además de en la duración de [r], en la duración de [n] y [1], pero no en la de $[\mathrm{m}]$ y $[\Lambda]$. 


\begin{tabular}{||l|l||c|c|c||}
\hline \multicolumn{2}{|c|}{ Consonante } & [+ Acento] & [- Acento] & $\mathrm{P}$ \\
\hline \hline $\mathrm{s}$ & $\mathrm{n}$ & 51 & 31 & 0,0368 \\
& $\mathrm{ms.}$ & 51 & 38 & \\
\hline $\mathrm{m}$ & $\mathrm{n}$ & 36 & 29 & 0,9427 \\
& $\mathrm{ms.}$ & 73 & 74 & \\
\hline $\mathrm{n}$ & $\mathrm{n}$ & 42 & 58 & 0,0222 \\
& $\mathrm{~ms}$. & 86 & 71 & \\
\hline $\mathrm{l}$ & $\mathrm{n}$ & 36 & 27 & 0,0118 \\
& $\mathrm{ms.}$ & 66 & 50 & \\
\hline$\kappa$ & $\mathrm{n}$ & 17 & 17 & 0,4468 \\
& $\mathrm{~ms}$. & 70 & 65 & \\
\hline \hline
\end{tabular}

TABLA 4. Duración de nasales, laterales

y [r] según el carácter acentuado o no de

la sillaba en que se encuentra.

Tanto [r] como [l] y [n] son siempre más largas si están en sílaba tónica, con una diferencia respecto de la posición átona que se sitúa entre los 13-16 ms. (17-25 $\%$ ). Este comportamiento queda reflejado en la Figura 2.

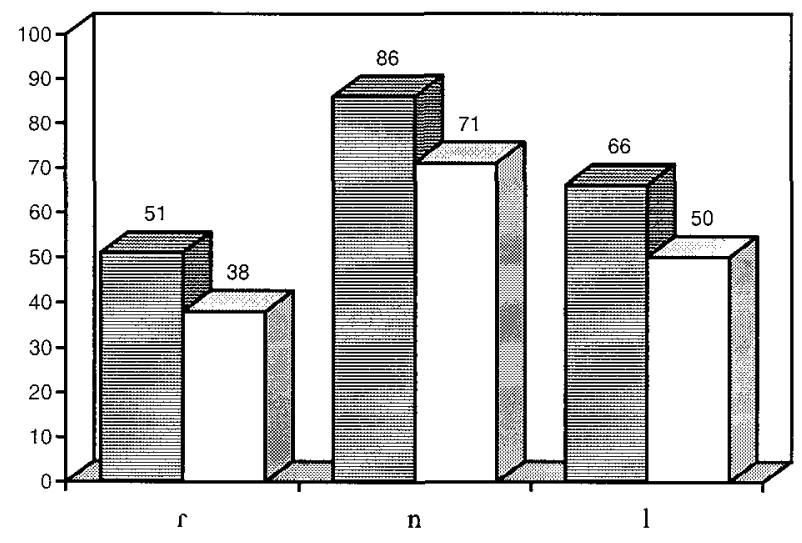

$$
\text { 目 [+ Acento] } \square[\text { - Acento }]
$$

Figura 2. Duración de [r], [I] y [n] segúin el acento. 


\subsection{Posición en la sílaba}

La posición del segmento en la sílaba es una variable que no afecta de forma homogénea a las consonantes del castellano. Este comportamiento se debe, por una parte, a la distribución defectiva que presentan ciertos elementos del sistema fonológico. No existen en coda silábica ni las palatales $[\mathrm{n}],[K]$ y $\left[\mathrm{t} \int\right]$, ni $[\mathrm{r}]$. En cuanto a las fricativas sonoras, $[y]$ sólo aparece en ataque y $[\mathrm{z}]$, en cambio, está restringida a la distensión silábica.

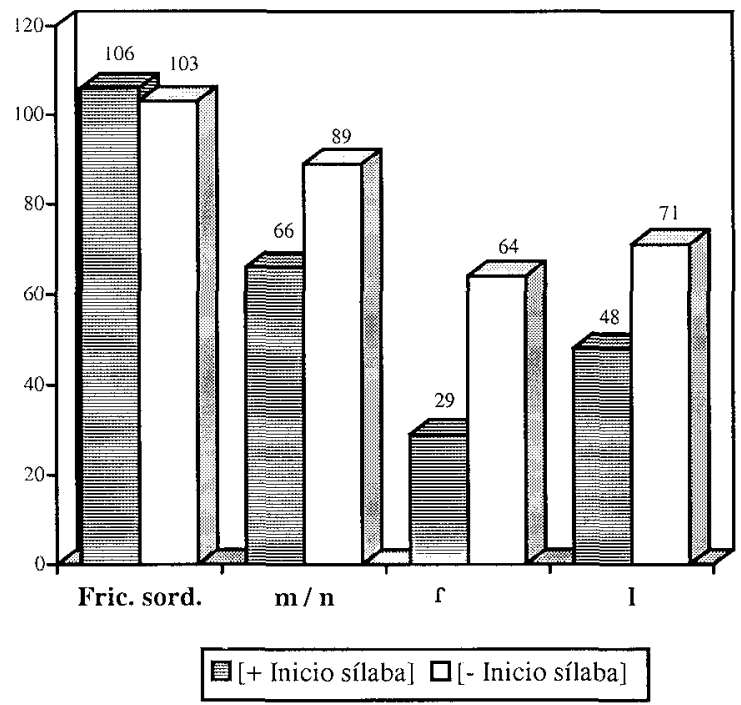

Figura 3. Duración de las fricativas sordas, $[\mathrm{m}],[\mathrm{n}],[\mathrm{r}]$ y ll] según la posición en la sílaba.

Por otra parte, entre los segmentos que potencialmente pueden quedar afectados por la posición en la sílaba, se observa un comportamiento dispar (Figura 3). Mientras las fricativas sordas no sufren variaciones estadísticamente significativas en su duración según se encuentren o no en inicio de sílaba se aprecia un alargamiento en posición final de sílaba de [m], [n], (23 ms., que equivale al 25' 8 $\%$ ) [l] (23 ms., un 32\% \%) y [r] (35 ms., un 54,5\%). Es interesante constatar, además, que este incremento en la duración afecta sólo a consonantes sonoras.

No debe sorprendernos el hecho de que un t-test realizado con el conjunto de las consonantes dé como resultado que la posición en la sílaba no es una variable que afecte a la duración consonántica, dada la alta proporción de fricativas sordas en el total de las consonantes estudiadas. A su vez, si se estudian por separado [f], [ $\theta]$, [s] 
y [x] los resultados no difieren de los obtenidos en el análisis conjunto de las fricativas sordas.

\begin{tabular}{||c|l||c|c|c||}
\hline \hline \multicolumn{2}{|l|}{ Subclase } & [+ In. síl.] & [- In. síl.] & P \\
\hline \hline Fricativas & n & 133 & 66 & 0,5118 \\
sordas & ms. & 106 & 103 & \\
\hline $\mathrm{m} / \mathrm{n}$ & $\mathrm{n}$ & 94 & 71 & 0,0001 \\
& ms. & 66 & 89 & \\
\hline r & n & 43 & 39 & 0,0001 \\
& ms. & 29 & 64 & \\
\hline I & n & 32 & 31 & 0,0001 \\
& ms. & 48 & 71 & \\
\hline Total & n & 302 & 207 & 0,1266 \\
& ms. & 76 & 86 & \\
\hline
\end{tabular}

TABLA 5. Duración de las fricativas sordas, $[\mathrm{m}],[\mathrm{n}] \mathrm{y}$ [l] según su posición en la sílaba.

\subsection{Posición en el grupo fónico}

La posición en el grupo fónico es un factor que afecta de forma clara a la duración de las consonantes estudiadas. La TABLA 6 recoge el conjunto de los datos obtenidos. En el grupo de las fricativas sonoras sólo se ha analizado [y], ya que la aparición de [z] está condicionada contextualmente: únicamente es posible ante una consonante sonora. En cambio, se han incluido en el estudio todos aquellos sonidos que, aunque no puedan aparecer como último segmento del grupo fónico, sí aparecen en el ataque de una sílaba prepausal.

Los resultados que se presentan en la Tabla 6 y en la Figura 4 muestran un alargamiento sistemático de los sonidos en posición prepausal $\mathrm{y}$, como puede observarse, el $t$-test da en todos los casos resultados altamente significativos. La media de duración de las consonantes en posición prepausal es de $98 \mathrm{~ms}$; este valor medio contrasta con el de las no prepausales, que se sitúa en $70 \mathrm{~ms}$, lo cual supone un incremento de $28 \mathrm{~ms}$. (un $40 \%$ ). 


\begin{tabular}{||c|l||c|c|c||}
\hline \hline Subclase & & [+ Prepausal] & [-Prepausal] & $\mathrm{P}$ \\
\hline $\mathrm{y}$ & $\mathrm{n}$ & 11 & 23 & 0,0034 \\
& $\mathrm{~ms}$. & 73 & 60 & \\
\hline Fricativas & $\mathrm{n}$ & 89 & 110 & 0,0001 \\
sordas & $\mathrm{ms.}$ & 123 & 91 & \\
\hline $\mathrm{M} / \mathrm{n}$ & $\mathrm{n}$ & 56 & 109 & 0,0001 \\
& $\mathrm{~ms}$. & 91 & 68 & \\
\hline $\mathrm{n}$ & $\mathrm{n}$ & 17 & 23 & 0,0068 \\
& $\mathrm{~ms}$. & 104 & 80 & \\
\hline $\mathrm{r}$ & $\mathrm{n}$ & 37 & 45 & 0,0023 \\
& $\mathrm{~ms}$. & 55 & 38 & \\
\hline $\mathrm{r}$ & $\mathrm{n}$ & 14 & 16 & 0,0377 \\
& $\mathrm{~ms}$. & 108 & 85 & \\
\hline $\mathrm{t} j$ & $\mathrm{n}$ & 12 & 18 & 0,0018 \\
& $\mathrm{~ms}$. & 143 & 100 & \\
\hline Laterales & $\mathrm{n}$ & 38 & 59 & 0,0001 \\
& $\mathrm{~ms}$. & 74 & 51 & \\
\hline Total & $\mathrm{n}$ & 274 & 403 & 0,0001 \\
& $\mathrm{~ms}$. & 98 & 70 & \\
\hline
\end{tabular}

TABLA 6. Duración según la posición en el grupo fónico.

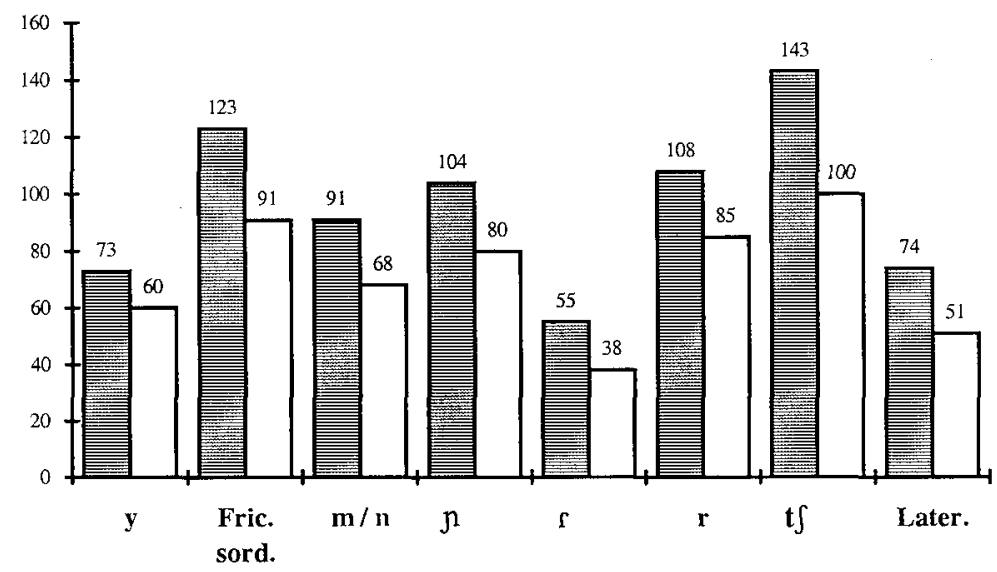

鴠[+ Prepausal] ㅁ.- Prepausal $]$

Figura 4. Duración según la posición en el grupo fónico. 


\subsection{Interacción entre las variables}

Una observación minuciosa de la TABLA 2 revela que las consonantes experimentan mayores variaciones duracionales en coda silábica que en ataque. Este comportamiento se pone claramente de manifiesto en la Figura 5, donde se

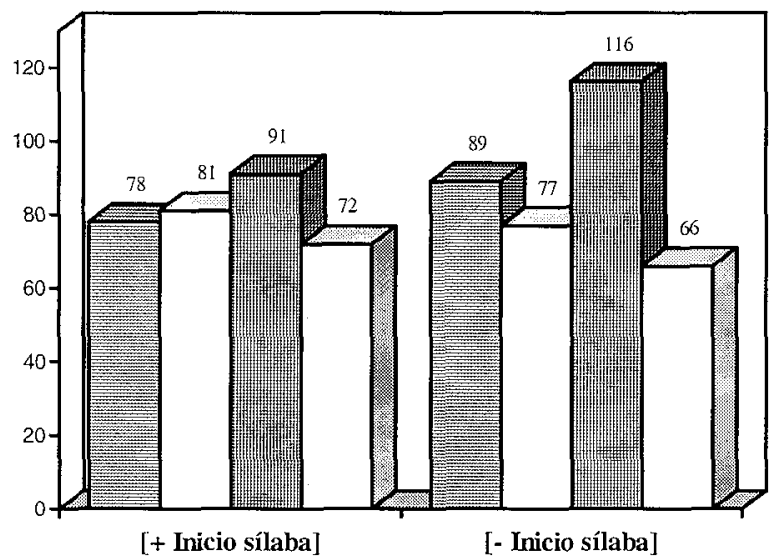

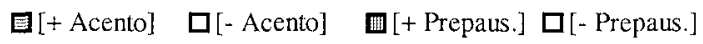

Figura 5. Duración media de las consonantes según el acento, la posición en el grupo fónico y la posición en la sílaba.

compara la media de las duraciones consonánticas para las variables acento y posición en el grupo fónico desglosadas en los contextos [+/- inicio de sílaba]. En efecto, la diferencia entre las duraciones de una consonante en sílaba tónica o en átona es de $3 \mathrm{~ms}$. cuando el segmento está en ataque; mientras que estas diferencias alcanzan los $12 \mathrm{~ms}$. en coda. Asimismo, las variaciones debidas al efecto de las pausas son de $19 \mathrm{~ms}$. en ataque y de $50 \mathrm{~ms}$. en distensión silábica.

La constatación de esta asimetría en el comportamiento de las consonantes en inicio y final de sílaba ha sugerido la necesidad de un examen más detenido del fenómeno. Para ello se ha dividido el conjunto de los datos obtenidos de las mediciones en dos grupos -el de las consonantes en ataque y el de las consonantes en coda - y se ha estudiado de qué manera inciden las variables [+/acento] y [+/- prepausal] en cada uno de ellos ${ }^{8}$.

\footnotetext{
${ }^{8}$ En este estudio no quedan incluídas todas las consonantes puesto que, como se afirmaba con anterioridad, algunas de ellas presentan una distribución defectiva.
} 


\subsubsection{Acento}

La TABLA 7 proporciona las duraciones medias de las consonantes tónicas y átonas en sendas columnas para inicio y final de sílaba. Un análisis de estos resultados confirma la tendencia antes enunciada, según la cual existe mayor variabilidad en coda, puesto que no se aprecian diferencias significativas en la duración de ninguna subclase de consonantes en contexto de ataque silábico.

\begin{tabular}{||c|l||c|c|c||c|c|c||}
\cline { 3 - 9 } \multicolumn{1}{c|}{} & \multicolumn{4}{c|}{ [+ Inicio sílaba] } & \multicolumn{4}{c||}{ [- Inicio sílaba] } \\
\hline \multicolumn{2}{||c|}{ Subclase } & {$[+\mathrm{Ac}]$} & {$[-\mathrm{Ac}]$} & $\mathrm{P}$ & {$[+\mathrm{Ac}]$} & {$[-\mathrm{Ac}]$} & $\mathrm{P}$ \\
\hline \hline Fricativas & $\mathrm{n}$ & 63 & 70 & 0,6128 & 41 & 24 & 0,5287 \\
sordas & $\mathrm{ms}$ & 105 & 108 & & 106 & 99 & \\
\hline $\mathrm{m}$ & $\mathrm{n}$ & 26 & 19 & 0,8361 & 10 & 10 & 0,5697 \\
& $\mathrm{~ms}$. & 72 & 71 & & 76 & 78 & \\
\hline $\mathrm{n}$ & $\mathrm{n}$ & 20 & 29 & 0,2284 & 22 & 29 & 0,0301 \\
& $\mathrm{~ms}$ & 64 & 58 & & 107 & 84 & \\
\hline $\mathrm{f}$ & $\mathrm{n}$ & 24 & 19 & 0,8494 & 27 & 14 & 0,0400 \\
& $\mathrm{~ms}$. & 28 & 30 & & 70 & 52 & \\
\hline $\mathrm{I}$ & $\mathrm{n}$ & 17 & 15 & 0,8299 & 19 & 14 & 0,0054 \\
& $\mathrm{~ms}$ & 48 & 47 & & 81 & 53 & \\
\hline
\end{tabular}

TABLA 7. Duración en inicio y final de sílaba según el acento.

Como se puede observar en la Figura 6 y en la Figura 7, las tres consonantes para las cuales el acento se había revelado como una variable cuya incidencia provocaba diferencias estadísticamente relevantes presentan variaciones significativas tan solo cuando están en coda: únicamente para [n], [1] y [r] en este contexto el valor de $p$ obtenido con el $t$-test es inferior a $0,05^{9}$. En dicha posición, estas consonantes tienen una duración mayor en sílaba tónica que en sílaba átona, con un incremento en su duración que oscila entre 18 y $28 \mathrm{~ms}$., lo cual supone un aumento de entre el 28 y el $53 \%$.

\footnotetext{
9 Podría ser, no obstante, que en el contexto final de sílaba existiera una influencia del alargamiento prepausal, que afecta de forma mucho más clara a las consonantes en coda. Por tanto, deberia estudiarse con un número mayor de casos el comportamiento de estas tres consonantes en relación al acento.
} 


\begin{tabular}{||c|l||c|c|c|c|c|c||}
\cline { 3 - 8 } \multicolumn{1}{c|}{} & \multicolumn{3}{c|}{ [+ Inicio sílaba] } & \multicolumn{4}{c||}{ [-Inicio sílaba] } \\
\hline \hline Subclase & & {$[+$ Pre] } & {$[-$ Pre] } & P & {$[+$ Pre] } & {$[-$ Pre] } & P \\
\hline \hline Fricativas & $\mathrm{n}$ & 53 & 80 & 0,0001 & 36 & 29 & 0,0001 \\
sordas & $\mathrm{ms}$ & 120 & 97 & & 127 & 74 & \\
\hline $\mathrm{n}$ & $\mathrm{n}$ & 20 & 29 & 0,7743 & 18 & 33 & 0,0001 \\
& $\mathrm{~ms}$. & 62 & 60 & & 136 & 71 & \\
\hline $\mathrm{r}$ & $\mathrm{n}$ & 18 & 25 & 0,0865 & 21 & 22 & 0,0002 \\
& $\mathrm{~ms}$ & 30 & 29 & & 79 & 50 & \\
\hline $\mathrm{l}$ & $\mathrm{n}$ & 10 & 22 & 0,0030 & 13 & 18 & 0,0001 \\
& $\mathrm{~ms}$ & 58 & 43 & & 103 & 50 & \\
\hline
\end{tabular}

TABLA 8. Duración en inicio y final de sílaba según la posición en el grupo fónico.

Se aprecia en la Figura 8 que, en coda silábica, las variaciones debidas a la posición del segmento en el grupo fónico son notorias: el incremento en posición prepausal es siempre superior al $58 \%$. El aumento experimentado por cada uno de los grupos de consonantes en posición prepausal es el siguiente:

-Fricativas sordas: $53 \mathrm{~ms} .(71,6 \%)$

-[n]: $65 \mathrm{~ms} .(91,5 \%)$.

- [r]: $29 \mathrm{~ms} .(58,1 \%)$.

-[1]: $53 \mathrm{~ms} .(106 \%)$.

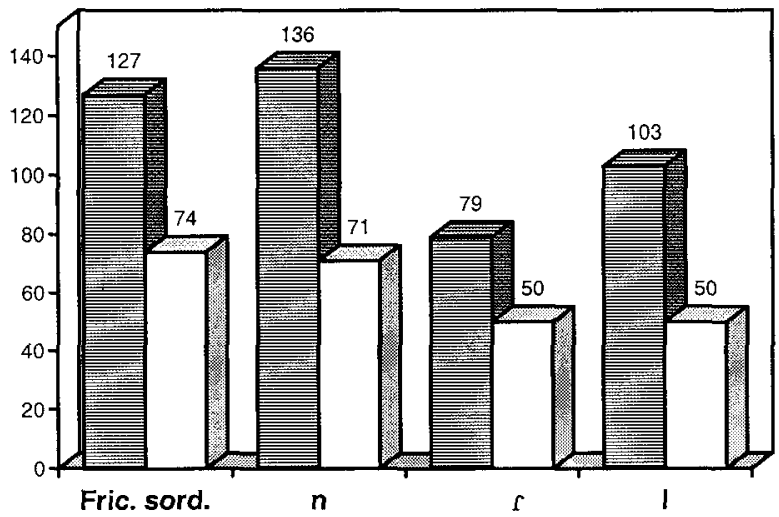

目[+ Prepausal $]$ 口[- Prepausal $]$

Figura 8. Duración en posición final de sílaba según la posición en el grupo fónico. 


\section{Discusión de los resultados}

En este apartado se cotejarán los resultados de nuestro análisis con los que proporcionan investigaciones previas, dedicando una especial atención a la bibliografía existente para el castellano. Un inconveniente radica en el hecho de que los corpus que sirven de base a los trabajos de Navarro Tomás (1918) y Borzone y Signorini (1983) son de distinta naturaleza que el que se viene manejando para este estudio, puesto que aquéllos están constituidos por palabras aisladas y el nuestro, en cambio, es un corpus formado por un conjunto de textos extraídos de la prensa diaria. Luego no es de extrañar que los resultados de estos autores difieran de los presentados aquí, dado que de los análisis efectuados a partir de palabras aisladas resultan siempre valores absolutos mayores. No obstante, aunque no es lícito confrontar directamente las duraciones totales, sí cabe contrastar las diferencias de duración en términos proporcionales.

Según Navarro Tomás (1918), las consonantes más largas del español son las fricativas sordas. Dentro de este grupo, establece que $[\mathrm{f}]$ y $[\mathrm{x}]$ tienen una duración mayor que $[s]$ y $[\theta]$. En nuestro análisis se ha llegado a conclusiones similares, aunque según los datos obtenidos [ $\mathrm{t}\}$ ] es el segmento consonántico más largo. En la clase de las fricativas, es posible establecer, a tenor de los resultados obtenidos de nuestro análisis, una gradación análoga a la propuesta por Navarro:

$$
[\mathrm{f}]>[\mathrm{x}]>[\mathrm{s}]>[\theta]
$$

A su vez, tanto Navarro Tomás (1918) como Borzone \& Signorini (1983) afirman que las clases de las nasales y las laterales tienen una duración menor que las fricativas sordas pero mayor que las fricativas sonoras, que a su vez son más largas que [ $\mathrm{f}]$. Nuestro estudio, según se colige de la observación de las tablas 1 y 2 , llega a conclusiones muy próximas, puesto que, de acuerdo con las mediciones efectuadas, las consonantes del castellano se ordenan, de mayor a menor duración media, como sigue:

-Africada: $117 \mathrm{~ms}$.

-Fricativas sordas: $115 \mathrm{~ms}$.

—Vibrante múltiple: $96 \mathrm{~ms}$.

-Nasales: [n] $90 \mathrm{~ms}$.

$[\mathrm{m} / \mathrm{n}] 76 \mathrm{~ms}$.

-Fricativas sonoras: $63 \mathrm{~ms}$.

-Laterales: $60 \mathrm{~ms}$.

-Vibrante simple: $46 \mathrm{~ms}$.

Donde, sin embargo, las laterales, contrariamente a los resultados presentados en los citados estudios, tienen una duración sensiblemente menor 
que las fricativas sonoras, aunque las diferencias que observamos entre ambos grupos son mínimas (63 vs. 60 ms.).

Entre los trabajos dedicados a otras lenguas, merecen nuestra atención Crystal \& House (1988a), quienes sostienen que las africadas son más largas que las fricativas, y las fricativas sordas más que las sonoras, afirmaciones ambas que están en consonancia con los resultados que se desprenden del presente estudio.

Se ha puesto a menudo en relación la duración con la sonoridad. Chen (1970), Raphael (1981), Luce \& Charles-Luce (1985) y Klatt (1976) defienden que las oclusivas sordas del inglés tienen una mayor duración que las sonoras. Asimismo, según Navarro Tomás (1918), las consonantes sordas en castellano son, en general, más largas que las sonoras, conclusión con la que coinciden los resultados de este estudio ${ }^{10}$.

El estudio de la influencia del acento en la duración consonántica no ofrece, en la bibliografía existente, resultados homogéneos, aunque se percibe una tendencia general a considerar que esta variable afecta a un gran número de consonantes, de tal modo que éstas se alargan en sílaba tónica. Duez \& Nishinuma (1987) para el francés y Borzone \& Signorini (1983) para el castellano sostienen que el acento afecta a la duración del inventario consonántico de ambas lenguas sin restricción alguna, mientras que en italiano, según Farnetani \& Kori (1984), se alargan las consonantes tónicas a inicio de palabra, pero no en posición interior. Crystal \& House (1988a) también consideran que el acento es una variable que afecta a la duración de todas las consonantes inglesas con la excepción de las fricativas sordas y las nasales. Finalmente, en su estudio dedicado al ritmo del castellano, Ríos (1991) considera que el acento es un factor que tiene poca incidencia en la duración silábica.

La observación detallada de los resultados obtenidos para el castellano en nuestra investigación parece estar en consonancia con el análisis del comportamiento silábico expuesto por Ríos (1991). A partir del estudio estadístico de los valores extraídos de las mediciones, se concluye que el acento no afecta a la duración consonántica del castellano salvo en los casos de [n], [1] y [r] cuando aparecen en coda silábica. En este contexto, dichas consonantes tienen un incremento si están en sílaba tónica que oscila entre 18 y $28 \mathrm{~ms}$., lo cual supone un aumento de entre el 28 y el $53 \%$ con respecto a su duración en sílaba átona (Cf. la Figura 6). Para este comportamiento podría ofrecerse una hipótesis explicativa de base fonológica. En efecto, [n], [r], [1] se suelen clasificar en los estudios fonológicos dentro del conjunto de las llamadas sonantes, que se sitúan a medio camino entre las consonantes y las

\footnotetext{
${ }^{10}$ No obstante, véase la nota 6 .
} 
vocales; según esto, podría argumentarse que en relación al acento, el comportamiento de estos segmentos es el propio de las vocales, puesto que, como demuestran los estudios dedicados a la duración vocálica del castellano (Marín, 1994-95), las vocales tónicas sistemáticamente son más largas que las átonas ${ }^{11}$.

La relación entre la duración de una consonante y la posición que ésta ocupa en la sílaba es un aspecto al que sólo atienden algunos trabajos como el de Farnetani \& Kori (1984) y el de Campbell \& Isard (1991), quienes coinciden en afirmar que las consonantes se alargan en distensión silábica. Campbell \& Isard (1991) observan, además, que las consonantes en coda sufren mayores alargamientos que en ataque. También éste es el resultado que se deduce de nuestro análisis (Cf. $\S 3.2$ y $\S 3.4$ ).

Finalmente, el efecto de las pausas en la duración es uno de los aspectos más extensamente analizados en la bibliografía y sobre el cual hay un mayor consenso: la duración aumenta cuando un sonido se encuentra en posición prepausal. Todos los estudios coinciden en afirmar que, sin duda, dicho efecto tiene lugar en los sonidos vocálicos; sin embargo, no existe acuerdo sobre cuál es la influencia de las pausas en la duración de las consonantes. Para el español, Borzone \& Signorini (1983) constatan un alargamiento general de las consonantes en posición prepausal, mientras que Navarro Tomás (1918) resalta el aumento de la duración que experimenta /1/ en este contexto. Por su parte, Ríos (1991) halla que este alargamiento es muy claro en el ámbito de la sílaba.

Después de haber estudiado cómo quedan afectadas las consonantes españolas por el alargamiento prepausal $(\$ 3.4 .2)$ podemos concluir que el hecho de que una consonante aparezca en posición prepausal conlleva un alargamiento sistemático si la consonante se encuentra en coda silábica; alargamiento que siempre es superior al $60 \%$ y que puede alcanzar, en el caso de [1], el $106 \%$. En ataque, sin embargo, [n] y [r] —a diferencia de lo que ocurre con el resto de consonantes- no sufren modificaciones significativas.

\footnotetext{
$"$ Esta hipótesis, sin embargo, explica correctamente por qué el acento afecta sólo a consonantes sonantes, pero no da cuenta del hecho de que las demás consonantes sonantes $-[\mathrm{m}],[\mathrm{n}],[\mathrm{r}],[\kappa]$ - no experimentan variaciones significativas en su duración debidas a la influencia del acento. En este sentido cabe recordar que aunque en la tradición fonológica castellana no se considera que [n], [r] y [1] formen un grupo fonológico natural, en la bibliografía inglesa (Cf., por ejemplo, Chomsky \& Halle, 1968) estas consonantes se distinguen de las otras sonantes por el hecho de ser consonantes silábicas (esto es, con capacidad de ser núcleo silábico). Así, el incremento en la duración que experimentan estos segmentos como resultado del carácter acentual de la sílaba en que aparecen podría aducirse como prueba a favor de considerar estas tres consonantes como un grupo fonológico distinto también en castellano, prueba ésta que redundaría con las pruebas tanto fonéticas (estructura formántica clara) como fonológicas (capacidad de ser núcleo silábico en algunas lenguas) que se suelen traer a colación en las distintas propuestas de clasificación de las sonantes castellanas.
} 


\section{Conclusiones}

A pesar de la existencia de estudios generales como los de Navarro Tomás (1918) para el castellano peninsular y Borzone \& Signorini (1983) para el argentino, las investigaciones en el campo de la fonética experimental no han proporcionado todavía una descripción exhaustiva de los patrones duracionales del sistema consonántico del castellano. Esto tiene como consecuencia la ausencia de modelos publicados que caractericen la duración de las consonantes del español y que estén orientados hacia las aplicaciones que se desarrollan en el campo de las tecnologías del habla.

Nuestro estudio no viene a llenar este vacío; tan solo supone una primera aproximación a la cuestión. Se ha pretendido determinar la incidencia de tres factores -acento, posición en la sílaba y pausas- en la duración consonántica en la lectura a partir de un corpus de textos extraídos de la prensa periódica. Tras la revisión de la bibliografía fundamental en otras lenguas se han determinado cuáles eran los factores que presumiblemente podían modificar la duración consonántica en español. Los más importantes se han tenido en cuenta para la confección del corpus, ya como variables independientes del estudio, ya como variables no analizadas pero sí controladas. Se han estudiado las fricativas sordas, la fricativa palatal sonora y el alófono sonorizado de la fricativa alveolar, la africada palatal sorda, y las nasales, laterales y vibrantes.

El primer dato que se extrae de nuestro trabajo es la duración media de las consonantes. Analizadas estas duraciones se observa una tendencia de los sonidos consonánticos a agruparse de forma natural según su modo de articulación y según la sonoridad. La mayor duración corresponde a [t $\mathrm{t}]$, seguido de las fricativas sordas y de [r]; las nasales constituyen un grupo intermedio, y, finalmente, los segmentos fricativos sonoros y laterales, muy similares en su duración, son algo más largos que la vibrante simple, el segmento consonántico más breve de los analizados. Asimismo, en la mayor parte de las consonantes, la menor duración corresponde al mismo contexto: inicio de sílaba átona no prepausal; la interacción de diversos factores puede incrementar, en distinta proporción y bajo diferentes condiciones, esta duración mínima.

De las variables estudiadas, el acento es la que afecta a un conjunto de consonantes más reducido. Únicamente quedan afectadas por el carácter acentual de la sílaba en que se hallan [n], [1] y [r] cuando están en el contexto de coda. Precisamente, es en este contexto de distensión silábica donde las consonantes experimentan una mayor variabilidad. La posición que la consonante ocupa en la sílaba tiene, además, otro efecto en la duración: la 
mayor parte de los alófonos consonánticos (todos salvo las fricativas sordas) son más breves en ataque que en coda.

También afecta a la duración de las consonantes la posición que éstas ocupan en el grupo fónico. Todas las consonantes prepausales en coda silábica ven incrementada su duración en porcentajes de más del $60 \%$. En ataque este incremento es menor y no siempre se produce.

Con este estudio se pretende completar parcialmente la línea de trabajo iniciada por Marín (1994-95) y avanzar en la definición de un modelo de duración segmental del español aplicable especialmente a las tecnologías del habla.

\section{Referencias bibliográficas:}

Alarcos, E. (1971): Fonología española, Madrid: Gredos (Biblioteca Románica Hispánica, Manuales, 1).

Amerman, J. D. - Parnell, M. (1992): «Speech timing strategies in elderly adults», Journal of Phonetics, 20, págs. 65-76.

Borzone de Manrique, A. M. - Signorini, A. (1983): «Segmental Duration and Rythm in Spanish», Journal of Phonetics, 11, págs. 117-128.

Butler, C (1985): Statistics in Linguistics. Oxford: Basil Blackwell.

Campbell, W. M. - Isard, S. D. (1991): «Segment duration in a syllabe frame», Journal of Phonetics, 19,1, págs. 37-48.

Carlson, R. - Granström, B. (1986): «A search for durational rules in a real-speech database», Phonetica, 43, 3: 140-154.

Carlson, R. - Granström, B. (1989): «Modeling durational for different text materials», Proceeding of the European Conference on Speech Communication and Technology (II), Paris, vol. 2, págs. 328-331.

Chomsky, N. - Halle, M. (1968): The Sound Pattern of English, Cambridge (USA): MIT Press.

Crystal, T. H. - House, A. S. (1982): «Segmental Durations in Connected Speech Signals: Preliminary Results», Journal of the Acoustical Society of America, 72, 3, págs. 705-716.

Crystal, T. H. - House, A. S. (1988a): «Segmental Durations in Connected Speech

Signals: Current Results», Journal of the Acoustical Society of America, 83, 4, págs. 1553-1585.

Crystal, T. H. - House, A. S. (1988b): «Segmental durations in connected speech signals: syllabic stress», Journal of the Acoustical Society of America, 83, 4, págs. 1574-1585.

Crystal, T. H. - House, A. S. (1990): «Articulation rate and the duration of syllables and stress groups in connected speech», Journal of the Acoustical 
Society of America, 88, 1, págs. 101-112; in Kent, R. D. - Atal, B. S. - Miller, J. L. (eds.) (1991): Papers in Speech Communication: Speech Production. New York: Acoustical Society of America, págs. 433-444.

Delattre, P. (1966): «A comparison of syllable lenght conditioning among languages», International Review of Applied Linguistics, 7, 4, págs. 295-325.

Donegan, P. J. - D. Stampe (1983): «Rhythm and the holistic organization of language structure», in J. Richarson et al. (eds.), Papers from the parasession on the interplay of Phonology, Morphology and Syntax, Chicago Linguistic Society, University of Chicago, págs. 336-353.

Duez, D. - Nishinuma, Y. (1987/88): «Vitesse d'élocution et durée des syllabes et leurs constituants en français parlé», Travaux de l'Institut de Phonetique d'Aix, 11, págs. 157-180.

Eefting, W. (1991): "The effect of 'information value' and 'accentuation' on the duration of Duch words, syllables and segments", Journal of the Acoustical Society of America, 89, 1, págs. 412-424.

Engstrand, O. (1987): «Durational Patterns of Lule Sami Phonology», Phonetica, 44, págs. 117-128.

Farnetani, E. (1989): «Acoustic correlates of linguistic boundaries in Italian: a study of duration and fundamental frequency», Proceeding of the European Conference on Speech Communication and Technology (II), Paris, vol. 2, págs. 332-335.

Farnetani, E. - Kori, S. (1984): «Effects of syllable and word structure on segmental durations in spoken Italian», Quaderni del Centro di Studio per le ricerche di Fonetica (CNR), vol. III, págs. 143-188.

Farnetani, E. - Kori, S. (1986): «Effects of syllable and word structure on segmental duration in spoken Italian», Speech Comunication, 5, 1, págs. 17-34.

Fischer-Jørgesen, E. (1982): «Segment duration in Danish words in dependency on higher level phonological units», Annual Report of the Institute of Phonetics University of Copenhagen (ARIPUC), 16, págs. 137-189.

Gay et al. (1974): «Effect of Speaking Rate on Labial Consonant-Vowel Articulation», Journal of Phonetics, 2, págs. 47-63.

Goldberg, A. (1982): «Spectrographic analysis of the effect of vocalic context on the duration of $/ \mathrm{s} /$ production in normal-speaking children», Journal of the National Student Speech-Language-Hearing Association, 10, págs. 1-7.

Goldman-Eisler, F. (1968): Psycholinguistics: Experiments in Spontaneous Speech, New York: Academic Press.

Haggard, M. (1973a): «Abreviation of consonants in English pre- and post-vocalic clusters», Journal of Phonetics, 1, págs. 9-24.

Haggard, M. (1973b): «Correlations between succesive segment durations: values in clusters», Journal of Phonetics, 1, págs. 111-116. 
Harris, J. W. (1983): Syllable Structure and Stress in Spanish: A Nonlinear Analysis, Boston: M. I. T. Citamos por la traducción española La estructura silábica y el acento en español, Madrid: Visor (Lingüística y Conocimiento, 11), 1991.

Harris, M. S. - Umeda, N. (1974): «Effect of Speaking Mode on Temporal Factors in Speech», Journal of the Acoustical Society of America, 56, págs. 1016-1018.

Klatt, D. H. (1975): «Vowel Lenghthening is Syntactically Determinated in a Connected Discourse», Journal of Phonetics, 3, págs. 129-140.

Klatt, D. H. (1976): «Linguistic uses of segmental duration in English: acoustic and perceptual evidence», Journal of the Acoustical Society of America, 59, 5, págs. 1208-1221; in Kent, R. D. - Atal, B. S. - Miller, J. L. (eds.) (1991): Papers in Speech Communication: Speech Production, New York: Acoustical Society of America, págs. 503-516.

Klatt, D. H. (1979): «Synthesis by rule of segmental duration in English», en Lindblom, B. - Öhman, S. (Eds.), Frontiers of Speech Communication Research, London: Academic Press, págs. 287-299.

Lehiste, I. (1972): «The Timing of Utterances and Linguistic Boundaries», Journal of the_Acoustical Society of America, 51, págs. 2018-2024.

Lindblom, B. (1968): «Temporal organization of syllable production», KTH Speech Transmission Laboratory. Quarterly Report, 2-3/1968, págs. 1-15.

Luce, P. A. - Charles-Luce, J. (1985): «Contextual effects on vowel duration, clousure duration and the consonant/vowel ratio in speech production», Journal of the Acoustical Society of America, 78, 6, págs. 1949-1957.

Marín, R. (1994-95): «La duración vocálica en español», Estudios de Lingüística, 10, págs. 213-226.

Navarro Tomás, T. (1918): «Diferencias de duración entre las consonantes españolas», Revista de Filología Española, 5, págs. 367-393.

Nooteboom, S. G. - J. G. Kruyt (1987): «Accents, focus distribution, and the perceived distribution of given and new information: An experiment», Journal of the Acoustical Society of America, 82, págs. 1512-1524.

O'shaughnessy, D. (1974): «Consonant Duration in Clusters», IEEE Transactions on Acoustics, Speech and Signal Processing, ASSP, 22, págs. 285-295.

O'shaughnessy, D. (1981): «A study of French vowel and consonant durations», Journal of Phonetics, 9, págs. 358-406.

O'shaughnessy, D. (1984): «A Multispeaker Analysis of Durations in Read French Paragraphs», Journal of the Acoustical Society of America, 76, 6, págs. 16641672.

Olsen, C. L. (1972): «Rhythmical patterns and syllabic features of the Spanish sense-group», en A. Rigault \& R. Charboneau (eds.), Proceedings of the Seventh International Congress of Phonetic Sciences, Montreal 1971, The Hague \& Paris: Mouton, págs. 990-996. 
Oller, D. K. (1973): «The effect of position in utterance on speech segment duration in English», Journal of the Acoustical Society of America, 54, págs. 1235-1247.

Pitrelli, J. F. - Zue, V. W. (1989): «A hierarchical model for phoneme duration in American English», Proceedings of the European Conference on Speech Communication and Technology (II), Paris, págs. 324-327.

Quené, H. (1992): «Durational cues for word segmentation in Dutch», Journal of Phonetics, 20, págs. 331-350.

Quilis, A. (1965): «Phonologie de la quantité en espagnol», Phonetica, 13, págs. 82-85.

Quilis, A. (1981): Fonética acústica de la lengua española, Madrid: Gredos (Biblioteca Románica Hispánica, Manuales, 49).

Ríos, A. (1991): Caracterización acústica del ritmo castellano. Trabajo de investigación de Tercer Ciclo. Departamento de Filología Española, Universidad Autónoma de Barcelona.

Santen, J. P. H. van - Olive, J. P. (1990): «The analysis of contextual effects on segmental duration», Computer Speech and Language 4, 4, págs. 359-391.

Schwartz, M. F. (1969): «Influence of vowel environment on the duration of $/ \mathrm{s} /$ and /sh/», Journal of the Acoustical Society of America, 46, págs. 480-481.

Strangert, E. (1987): «Speech rate and the temporal structures of stressed and unstressed syllables in Swedish», RUUL, 17, págs. 22-28.

Srangert, E. (1988): «Syllable durations obtained from the KTH speech data base», KTH Speech Transmission Laboratory. Quartely Progress and Status Report, 4/1988, págs. 51-57.

Toledo, G. A. (1988): El ritmo en español. Estudio fonético con base computacional. Madrid: Gredos (Biblioteca Románcia Hispánica, Estudios y Ensayos, 361).

Umeda, N. (1977): «Consonant duration in American English», Journal of the Acoustical Society of America, 61, págs. 846-858. 